\title{
The six Rs of managing high-risk opioid prescribing
}

Ferghal Armstrong, Shalini Arunogiri, Matthew Y Frei, Dan I Lubman

\section{Background}

High-dose opioid prescribing is associated with an increased risk of harms, including death.

\section{Objective}

The aim of this article is to discuss the concept of high-risk opioid prescribing, as well as relevant management strategies for patients on $>100 \mathrm{mg}$ oral morphine equivalent daily dose (OMEDD). The six 'Rs' approach to managing high-risk opioid prescribing (Rotation of opioids; Reduction; Replacement pharmacotherapy; Reversal with naloxone; Referral; Restriction of supply) is discussed.

\section{Discussion}

The six Rs is an aide-memoire that summarises the management options available to mitigate the risk of high OMEDDs. However, an effective therapeutic alliance between clinician and patient remains the foundation of all risk mitigation strategies.
THE US OPIOID CRISIS, associated with an estimated 130 opioid-related deaths per day, ${ }^{1}$ has led to a global shift in the regulation and management of opioid prescribing for chronic non-cancer pain (CNCP). ${ }^{2}$ In Australia, Pharmaceutical Benefits Scheme (PBS)-subsidised opioid prescriptions rose from 2.4 million in 1992 to 7.5 million in $2012,{ }^{3}$ with associated increases observed in pharmaceutical opioid-related deaths. ${ }^{4}$

Oral morphine equivalent daily dose (OMEDD) is a marker of analgesic potency, and it allows comparisons between different opioids in terms of their ability to produce the same analgesia as would be expected from a given dose of morphine. ${ }^{5}$ Equianalgesic dose conversion is not an exact science: there is a lack of consistency between available conversion charts, and patient-related factors cause further variability. ${ }^{6}$ Nonetheless, the Faculty of Pain Medicine, Australian and New Zealand College of Anaesthetists (FPM ANZCA) has produced a free opioid calculator $\mathrm{app}^{7}$ for this purpose on the basis of its own dose equivalency chart. ${ }^{8}$

Research shows that high-dose opioids are associated with worse functional outcomes ${ }^{9}$ and an increased risk of death. One study showed a threefold increase in the risk of death at doses of $200 \mathrm{mg}$ OMEDD,${ }^{10}$ whereas other evidence suggests that an OMEDD of $>100 \mathrm{mg}$ elevates the risk of death by a factor of 11. ${ }^{11}$ Accordingly, The Royal Australian College of General Practitioners (RACGP) now recommends dose reductions at a threshold of $100 \mathrm{mg}$ OMEDD, ${ }^{12}$ which also serves as the trigger for a red flag in the state of Victoria's real-time prescription monitoring system, SafeScript.

The remainder of this article focuses on the management of patients taking opioid doses > $100 \mathrm{mg}$ OMEDD for CNCP in a primary care setting, excluding circumstances of acute pain, cancer pain and pain at the end of life. General practitioners and patients need to be aware of the risk of mortality when prescribing or taking an >100 mg OMEDD for CNCP.

\section{Management approaches}

The foundation of any risk management intervention is a robust therapeutic alliance. A non-judgemental and personcentred approach is essential to facilitate dialogue about the appropriate use of opioids and their risks. ${ }^{13}$ A greater position of safety is secured when patients are prescribed $\leq 100 \mathrm{mg}$ OMEDD. Opioid tapering or opioid rotation are central to the management of high OMEDDs; however, the management of patient risk associated with high OMEDDs may require additional interventions, such as opioid agonist therapy (OAT) in the context of an opioid use disorder (OUD), the use of naloxone, referral to other health practitioners and the restriction of supply.

Drawing on recommendations identified by Australian and international guidelines for opioid therapy and $\mathrm{CNCP},{ }^{2,12,14-17}$ the authors developed the 'six Rs' mnemonic (Box 1) as an aide-memoire for the range of interventions that can be helpful in the management of patient risk associated 
with high OMEDD prescribing in the context of CNCP. The six Rs provide a summary of management options available and can be used in any order on the basis of a personalised assessment of the patient's individual circumstances.

\section{Rotation of opioids}

Opioid rotation, whereby a patient is switched from one opioid to another, ${ }^{18,19}$ may provide a rapid means of reducing OMEDD without loss of analgesic efficacy..$^{20}$ Canadian guidance on the use of opioids for CNCP validates the use of opioid rotation as a 'as a way of facilitating ... dose reduction' ${ }^{14}$ Reduction in OMEDD during rotation relies on the fact that patients do not usually show cross-tolerance between opioids. ${ }^{14}$ Converting from one opioid to another mandates the use of a reduction in the calculated equianalgesic dose of the second opioid, first to avoid the risks of side effects including respiratory depression and overdose, and also to accommodate the variability of dose conversion charts and patient factors. The elderly, and those with hepatic or renal impairment, have a higher risk of accidental overdose and may require lower doses of the second opioid in an opioid rotation regimen. Drug-drug interactions also must be considered, given the possibility of dramatic fluctuations in serum levels of the second opioid. ${ }^{19}$ Such cautious prescribing of the second opioid during an opioid rotation could involve switching to approximately $50-75 \%$ of the calculated equianalgesic dose $\mathrm{e}^{14,18}$ of the second opioid.

For example, if a patient were prescribed morphine solution $20 \mathrm{mg}$ three times daily and morphine sulphate controlled-release $60 \mathrm{mg}$ twice daily, then the patient's total OMEDD would be $180 \mathrm{mg}$. According to the FPM ANZCA, $180 \mathrm{mg}$ is equivalent to $120 \mathrm{mg}$ oxycodone. If one were to prescribe this dose, then the patient, because of a lack of cross tolerance, would likely have side effects including sedation and respiratory depression. It would therefore be prudent to reduce the dose of the second opioid by approximately $25-50 \%$ of the calculated equivalent dose, which in this case would be oxycodone $30-45 \mathrm{mg}$ twice daily (or
60-90 mg per day). According to the FPM ANZCA, $60 \mathrm{mg}$ oxycodone is equivalent to $90 \mathrm{mg}$ morphine, while $90 \mathrm{mg}$ is equivalent to approximately $135 \mathrm{mg}$. This rotation from morphine to oxycodone therefore results in a final total daily dose that is $50-75 \%$ of the original dose, significantly reducing the total OMEDD.

\section{Reduction (tapering) of OMEDD}

Opioid tapering (ie a gradual reduction in dose over weeks to months) is another method of achieving a reduction in OMEDD for a patient prescribed high-dose opioids. ${ }^{21,22}$ For patients prescribed very high OMEDD, tapering may need to follow opioid rotation. Patients can have their dose reduced at a rate of approximately $10 \%$ of the starting dose per week (Box 2). GPs may find that opioid reduction templates are a useful resource when planning opioid tapers. ${ }^{23}$

Patient cooperation with opioid tapering is essential, and any decision to taper needs careful explanation of indications, benefits, contraindications and risks. The main indication for opioid tapering is patient safety. It has already been discussed that high OMEDDs of $>100 \mathrm{mg}$ can elevate the risk of death; ${ }^{10,11}$ however, other considerations, including the side effects of long-term opioid use, may affect the decision to commence tapering (eg opioid-induced hyperalgesia, whereby opioids are responsible for worsening of pain, ${ }^{24}$ and opioid-induced hypogonadism ${ }^{25}$ ).

The indication for long-term opioid use may need to be reviewed in light of recent evidence suggesting that opioids cause more harm and provide less effective analgesia than non-opioid treatment options in the management of osteoarthritis-related pain. ${ }^{26}$ Beyond a reduction in the risk of death, there is weak evidence of the benefits of opioid tapering in terms of a reduction in pain and an improvement in function and quality of life. ${ }^{27}$ Patients may fear a worsening of pain during a taper; however, this has not been supported by evidence for tapering from a recent Cochrane review. ${ }^{28}$

Tapering should not be considered without specialist input for conditions such as cancer pain, acute pain, and new or ongoing tissue damage. ${ }^{29}$ Where there is a diagnosis of OUD, opioid tapering is not considered an alternative to OAT. Because of the risks of opioid withdrawal, tapering during pregnancy is not recommended. ${ }^{30}$

Opioid tapering is associated with concerns regarding the emergence of psychological symptoms or exacerbations of pre-existing psychiatric conditions. The RACGP lists unstable medical and psychiatric conditions as a precaution for opioid tapering..$^{30}$ Evidence suggests that patients with a pre-existing diagnosis of depression are more likely to drop out of an opioid taper program, and that those who did drop out of an opioid taper program rated their depressive symptoms as worse than baseline prior to the taper, ${ }^{31}$ although it is not clear that the taper itself caused a worsening of depressive symptoms. Nonetheless, the US Centers for Disease Control and Prevention recommends a tapering plan that includes the provision of psychosocial support and monitoring for the emergence of psychological symptoms. ${ }^{15}$ However, concern regarding worsening of psychological function or the emergence of anxiety during an opioid

\section{Box 1. The six Rs of managing high-risk opioid prescribing}

- Rotation of opioids

- Reduction (tapering)

- Replacement pharmacotherapy

- Reversal with naloxone

- Referral to allied health practitioners/ other specialists

- Restriction of supply

\section{Box 2. Opioid taper}

- All opioids (both short- and long-acting) are converted into one long-acting opioid (may involve opioid rotation).

- The dose of the long-acting opioid is decreased at a rate of $10 \%$ of the starting dose per week or fortnight.

- The use of short-acting opioids or as-needed doses is strictly limited.

- Non-opioid analgesics are used to manage pain flares.

- Opioid withdrawal symptoms are managed by reducing the taper rate. 
taper was not substantiated in a recent Cochrane review of opioid tapering. ${ }^{28}$

Where there is patient distress during an opioid taper - as evidenced by symptoms of dysphoria, fatigue or sleep disturbance - chronic opioid withdrawal needs to be considered. ${ }^{32}$ Such symptoms need to be managed in a caring therapeutic relationship and may necessitate a reduction in the speed of the taper. Benzodiazepines are not recommended for the management of anxiety during a taper. ${ }^{23}$ It is recommended that addiction specialist advice be sought on this issue; however, in most cases, persisting with tapering is worthwhile given the risks associated with opioid doses above $100 \mathrm{mg}$ OMEDD.

\section{Replacement pharmacotherapy (opioid agonist therapy)}

It has been estimated that up to $30 \%$ of patients prescribed long-term opioids develop aberrant behaviours related to their prescription opioids (eg medically unsanctioned use, dose escalation, lost prescriptions or prescription forgery). ${ }^{33}$ In such cases, it is important to consider the diagnosis of an OUD as defined by the Diagnostic and statistical manual of mental disorders, fifth edition. ${ }^{34}$ Patients presenting with symptoms of OUD are likely to benefit from OAT with buprenorphine or methadone. ${ }^{17}$ Where a patient with an OUD refuses OAT, addiction specialist advice should be sought. Each state and territory in Australia provides accredited pharmacotherapy prescribing training for clinicians covering clinical issues, practical considerations and local regulations.

\section{Reversal with naloxone}

High-dose opioids carry a risk of overdose and respiratory depression. The Community Overdose Prevention Education program provides training on harm reduction interventions, including the use of naloxone. ${ }^{35}$ Naloxone, a mu-opioid receptor antagonist, reverses the effects of opioid overdose. ${ }^{36}$ In Australia it is available as a vial, prefilled syringe or nasal spray. Naloxone, and accompanying training on its administration, should be offered to all patients who are at risk of opioid overdose, including those on high-risk opioid medications. ${ }^{9}$ Guidance suggests that the threshold for considering naloxone supply should be $50 \mathrm{mg}$ OMEDD. ${ }^{2}$ Training can

Table 1. Addiction specialist telephone advisory services*

\begin{tabular}{lll}
\hline State or territory & Service & Telephone number \\
\hline Victoria & $\begin{array}{l}\text { Drug and Alcohol Clinical } \\
\text { Advisory Service }\end{array}$ & 1800812804 \\
\hline Tasmania & $\begin{array}{l}\text { Drug and Alcohol Clinical } \\
\text { Advisory Service }\end{array}$ & 1800630093 \\
\hline Northern Territory & $\begin{array}{l}\text { Drug and Alcohol Clinical } \\
\text { Advisory Service }\end{array}$ & 1800111092 \\
\hline South Australia & $\begin{array}{l}\text { Drug and Alcohol Clinical } \\
\text { Advisory Service }\end{array}$ & (08) 70871742 \\
\hline Western Australia & Clinical Advisory Service & (08) 94425042 \\
\hline $\begin{array}{l}\text { New South Wales/Australian } \\
\text { Capital Territory }\end{array}$ & $\begin{array}{l}\text { Drug and Alcohol Specialist } \\
\text { Advisory Service }\end{array}$ & (02) 93618006 \\
\hline Queensland & $\begin{array}{l}\text { Alcohol and Drug Clinical } \\
\text { Advisory Service }\end{array}$ & 1800 290928 \\
\hline
\end{tabular}

*General practitioners wishing to speak with an alcohol and other drug (AOD) specialist for secondary advice may contact their local AOD service or their state's telephone AOD specialist consultancy service. These numbers are not for patients and are for use by health professionals only.

be as basic as identification of features of toxicity and the administration of intranasal or intramuscular naloxone. ${ }^{37}$

\section{Referral}

Referral to psychologists, physiotherapists and other allied health practitioners should be encouraged as part of a multimodal system of CNCP management, ${ }^{38}$ given that psychological and physical therapies can help de-emphasise the role of prescribed opioids. Referral to an accredited pharmacist for a Domiciliary Medication Management Review facilitates a comprehensive assessment of the overall safety of prescribing and facilitates further discussion regarding prescribing options. ${ }^{16}$ Referral to a psychologist or a psychiatrist should be considered where there are mental health comorbidities, complex emotional trauma, poor coping skills and pain-catastrophising. ${ }^{39}$ Referral to an addiction specialist or a pain physician can help inform long-term plans, such as initiation of pharmacotherapy or opioid reduction strategies. Free, confidential addiction specialist advice is also available across all Australian jurisdictions (Table 1).

\section{Restriction of supply}

It is not mandatory to prescribe standard PBS quantities of opioids. Reduced quantities can be prescribed when there is a concern regarding high-dose opioid use. ${ }^{40}$ This approach facilitates increased frequency of face-to-face consultations with the prescriber, thereby enhancing monitoring of opioid therapy. Limited dispensing, ${ }^{41}$ whereby patients attend a pharmacy regularly to receive staged quantities of medication (eg daily or weekly), allows the pharmacist to monitor medication consumption patterns. Limited dispensing is a cornerstone of OAT and can be a useful intervention for patients in receipt of high-risk opioid prescriptions.

\section{Conclusion}

Patients prescribed opioids at doses $>100 \mathrm{mg}$ OMEDD have an elevated mortality risk. The 'six Rs' aide-memoire, based on current national and international guidelines, offers an easy-toremember mnemonic of risk mitigation 
strategies for the management of high-risk opioid prescribing. However, such approaches are underpinned by a robust therapeutic alliance between the doctor and their patient.

\section{Key points}

- The use of high-dose opioids (>100 mg OMEDD) in the management of CNCP increases the risk of death.

- Patients prescribed high doses of opioids need to be managed appropriately to reduce risks of morbidity and mortality.

- The foundation of any risk management strategy is the therapeutic alliance between the patient and the clinician.

- The 'six Rs' mnemonic may help clinicians implement interventions that reduce the risks associated with $>100 \mathrm{mg}$ OMEDD.

\section{Authors}

Ferghal Armstrong FRACGP, Addiction Medicine Registrar, Turning Point, Eastern Health, Vic Shalini Arunogiri MBBS (Hons), MSc, MPsychiatry, PhD, FRANZCP, Addiction Psychiatrist, Clinical Lead Turning Point, Eastern Health, Vic; Senior Lecturer, Monash Addiction Research Centre and Eastern Health Clinical School, Monash University, Vic Matthew Y Frei FACHAM, Addiction Medicine Specialist, Clinical Director, Turning Point, Eastern Health, Vic

Dan I Lubman BSc (Hons), MBChB, PhD, FRANZCP, FAChAM, Director, Turning Point, Eastern Health, Vic; Professor of Addiction Studies, Monash University, Vic.Dan.Lubman@monash.edu

Competing interests: MYF reports personal fees from Reckitt-Benckiser, outside the submitted work. DL reports speaking honoraria and advisory board fees from Indivior; speaking honoraria from Camurus, Lundbeck, AstraZeneca, Janssen-Cilag, Servier and Shire; and grants from NHMRC, ARC, VicHealth, VRGF, Google and Camurus, outside the submitted work. FG reports grants from Indivior, outside the submitted work. SA reports speaking honoraria from Camurus, outside the submitted work. Funding: None.

Provenance and peer review: Commissioned, externally peer reviewed.

\section{References}

1. National Institute on Drug Abuse. Opioid overdose crisis. Bethesda, MD: NIDA, 2019. Available at www.drugabuse.gov/drugs-abuse/opioids/opioidoverdose-crisis [Accessed 21 October 2019].

2. Dowell D, Haegerich TM, Chou R. CDC guideline for prescribing opioids for chronic pain - United States, 2016. MMWR Recomm Rep 2016;65(No. RR-1):1-49. doi: 10.15585/mmwr.rr6501e1.

3. Blanch B, Pearson S-A, Haber PS. An overview of the patterns of prescription opioid use, costs and related harms in Australia. Br J Clin Pharmacol 2014;78(5):1159-66. doi: 10.1111/bcp.12446.
4. Monheit B, Pietrzak D, Hocking S. Prescription drug abuse - A timely update. Aust Fam Physician 2016:45(12):862-66.

5. Nielsen S, Degenhardt L, Hoban B, Gisev N. Comparing opioids: A guide to estimating oral morphine equivalents (OME) in research. Technical Report No. 329. Sydney, NSW: National Drug and Alcohol Research Centre, University of NSW, 2014.

6. Shaheen PE, Walsh D, Lasheen W, Davis MP, Lagman RL. Opioid equianalgesic tables: Are they all equally dangerous? J Pain Symptom Manage 2009;38(3):409-17. doi: 10.1016/j. jpainsymman.2009.06.004.

7. Faculty of Pain Medicine ANZCA. Opioid calculator - A new horizon in safety. Melbourne: FPM, 2016. Available at http://fpm.anzca.edu.au/ documents/opioid_calculator_app.pdf [Accessed 21 October 2019].

8. Faculty of Pain Medicine ANZCA. Opioid-doseequivalence. Melbourne: FPM, 2019. Available at https://fpm.anzca.edu.au/documents/opioiddose-equivalence.pdf [Accessed 21 October 2019].

9. Kidner CL, Mayer TG, Gatchel RJ. Higher opioid doses predict poorer functional outcome in patients with chronic disabling occupational musculoskeletal disorders. J Bone Joint Surg Am 2009;91(4):919-27.

10. Gomes T, Mamdani MM, Dhalla IA, Paterson JM, Juurlink DN. Opioid dose and drug-related mortality in patients with nonmalignant pain Arch Intern Med 2011;171(7):686-91. doi: 10.1001/ archinternmed.2011.117.

11. Gwira Baumblatt JA, Wiedeman C, Dunn JR, Schaffner W, Paulozzi LJ, Jones TF. Highrisk use by patients prescribed opioids for pain and its role in overdose deaths. JAMA Intern Med 2014;174(5):796-801. doi: 10.1001/ jamainternmed.2013.12711.

12. The Royal Australian College of General Practitioners. Prescribing drugs of dependence in general practice, Part C2: The role of opioids in pain management. East Melbourne, Vic: RACGP, 2017.

13. Sandhu H, Underwood M, Furlan AD, Noyes J, Eldabe S. What interventions are effective to taper opioids in patients with chronic pain? BMJ 2018;362:k2990. doi: 10.1136/bmj.k2990.

14. Busse JW, Craigie S, Juurlink DN, et al. Guideline for opioid therapy and chronic noncancer pain. CMAJ 2017;189(18):E659-66. doi: 10.1503/ cmaj.170363.

15. Centers for Disease Control and Prevention. Pocket Guide: Tapering opioids for chronic pain. Atlanta, GA: CDC, 2019.

16. Grinzi P. The inherited chronic pain patient. Aust Fam Physician 2016;45(12):868-72.

17. Gowing L, Ali R, Dunlop A, Farrell M, Lintzeris N. National guidelines for medication-assisted treatment of opioid dependence. Canberra: $\mathrm{DoH}$, 2014.

18. Fine PG, Portenoy RK. Establishing 'best practices' for opioid rotation: Conclusions of an expert panel. J Pain Symptom Manage 2009;38(3):418-25. doi: 10.1016/j.jpainsymman.2009.06.002.

19. Smith HS, Peppin J. Toward a systematic approach to opioid rotation. J Pain Res 2014;7:589-608. doi: 10.2147/JPR.S55782.

20. Hunter Integrated Pain Service. Reconsidering opioid therapy. Hunter New England, NSW: HIPS, 2014.

21. NPS MedicineWise. Recommendations for deprescribing or tapering opioids. Surry Hills, NSW: NPS MedicineWise, 2016.

22. Kral LA. Opioid tapering: Safely discontinuing opioid analgesics. Glenview, IL: Pain Treatment Topic, 2006
23. Oxford University Hospitals NHS Foundation Trust. Resources for GPs regarding opioids and chronic pain. Oxford: Oxford University Hospitals NHS Foundation Trust, 2019. Available at www. ouh.nhs.uk/services/referrals/pain/opioidschronic-pain.aspx [Accessed 21 October 2019].

24. Chu LF, Clark DJ, Angst MS. Opioid tolerance and hyperalgesia in chronic pain patients after one month of oral morphine therapy: A preliminary prospective study. J Pain 2006;7(1):43-48. doi: 10.1016/j.jpain.2005.08.001.

25. De Maddalena C, Bellini M, Berra M, Meriggiola MC, Aloisi AM. Opioid-induced hypogonadism: Why and how to treat it. Pain Physician 2012;15(3 Suppl):ES111-18. doi: 10.1016/j. mayocpiqo.2019.06.007.

26. Krebs EE, Gravely A, Nugent S, et al. Effect of opioid vs nonopioid medications on pain-related function in patients with chronic back pain or hip or knee osteoarthritis pain: The SPACE randomized clinical trial. JAMA 2018;319(9):872-82. doi: 10.1001/ jama.2018.0899.

27. Frank JW, Lovejoy TI, Becker WC, et al. Patient outcomes in dose reduction or discontinuation of long-term opioid therapy: A systematic review. Ann Intern Med 2017;167(3):181-91. doi: 10.7326/ M17-0598.

28. Eccleston C, Fisher $\mathrm{E}$, Thomas $\mathrm{KH}$, et al. Interventions for the reduction of prescribed opioid use in chronic non-cancer pain. Cochrane Database Syst Rev 2017;11:CD010323. doi: 10.1002/14651858.CD010323.pub3.

29. Dowell D, Haegerich T, Chou R. No shortcuts to safer opioid prescribing. N Engl J Med 2019;380(24):2285-87. doi: 10.1056/ NEJMp1904190.

30. The Royal Australian College of General Practitioners. Prescribing drugs of dependence in general practice, Part A - Clinical governance framework. East Melbourne, Vic: RACGP, 2015.

31. Heiwe $S$, Lönnquist I, Källmén H. Potential risk factors associated with risk for drop-out and relapse during and following withdrawal of opioid prescription medication. Eur J Pain 2011;15(9):966-70. doi: 10.1016/j. ejpain.2011.03.006.

32. Cohen ML. Principles of prescribing for persistent non-cancer pain. Aust Prescr 2013;36:113-15 doi: 10.18773/austprescr.2013.044.

33. Arunogiri S, Frei M, Lubman DI. Persistent noncancer pain in patients with addiction: Reflecting on the challenges. Medicine Today 2014;15(12):58-61.

34. American Psychiatric Association. Diagnostic and statistical manual of mental disorders: DSM-5. 5th edn. Arlington, VA: American Psychiatric Association Publishing, 2013.

35. Penington Institute. COPE - Overdose first aid. Carlton, Vic: Penington Institute, 2019. Available at www.penington.org.au/programs-and-campaigns/ resources/cope-overdose-first-aid/ [Accessed 21 October 2019].

36. Rzasa Lynn R, Galinkin JL. Naloxone dosage for opioid reversal: Current evidence and clinical implications. Ther Adv Drug Saf 2018;9(1):63-88. doi: 10.1177/2042098617744161.

37. Behar E, Santos GM, Wheeler E, Rowe C, Coffin PO. Brief overdose education is sufficient for naloxone distribution to opioid users. Drug Alcohol Depend 2015;148:209-12. doi: 10.1016/j. drugalcdep.2014.12.009.

38. NPS MedicineWise. Fact sheet. Chronic pain: what can I do? Surry Hills, NSW: NPS MedicineWise, 2015. 
39. Martel MO, Wasan AD, Jamison RN, Edwards RR. Catastrophic thinking and increased risk for prescription opioid misuse in patients with chronic pain. Drug Alcohol Depend 2013;132(1-2):335-41. doi: 10.1016/j.drugalcdep.2013.02.034.

40. Department of Health and Human Services. All reasonable steps and other key terms - Legislative requirements for health practitioners. Melbourne: DHHS, 2018.

41. Pharmaceutical Society of Australia. Guidelines for pharmacists providing staged supply services. Deakin West, ACT: Pharmaceutical Society of

Australia, 2017. Available at www.ppaonline.com.au/ wp-content/uploads/2019/01/PSA-Staged-SupplyGuidelines.pdf [Accessed 29 Janurary 2020]. 